\title{
Validation and evaluation of the psychometric properties of bangla nine-item Internet Disorder Scale-Short Form
}

\author{
Md. Saiful Islam , Md. Estiar Rahman, Mst. Sabrina Moonajilin \& Mark D. \\ Griffiths \\ To cite this article: Md. Saiful Islam , Md. Estiar Rahman, Mst. Sabrina Moonajilin \& Mark D. \\ Griffiths (2020): Validation and evaluation of the psychometric properties of bangla nine-item \\ Internet Disorder Scale-Short Form, Journal of Addictive Diseases \\ To link to this article: https://doi.org/10.1080/10550887.2020.1799134
}

\section{Validation and Evaluation of the Psychometric Properties of Bangla Nine-item Internet Disorder Scale-Short Form}

\begin{abstract}
Online activities such as online gaming and social media use have become very popular and for most individuals, engagement in such activities is highly enjoyable. However, for a small minority of individuals, such behaviors can lead to problematic internet use. There are many screening instruments that assess problematic internet use including the nine-item Internet Disorder Scale-Short-Form (IDS9-SF). The present study translated the IDS9-SF into Bangla and investigated its psychometric properties. The sample comprised 534 adolescents aged 13 to 18 years $(61.0 \%$ male; mean age 15.7 years $(\mathrm{SD}=1.5)$ from selected schools (secondary and higher secondary) in Dhaka City. The study included confirmatory factor analysis, Cronbach's alpha, and item-total correlation. Results demonstrated that the Bangla IDS9-SF had very good internal validity (Cronbach's alpha $=.82$ ), and that IDS score was positively and significantly correlated with scores on depression and anxiety scales. A confirmatory factor analysis showed the model had an excellent fit to the data. Therefore, the Bangla IDS9-SF appears to be a valid and reliable instrument that may be employed in further research on problematic internet use in Bangladesh.
\end{abstract}


Keywords: internet use; internet addiction; internet disorder; Bangladeshi adolescents; Internet Disorder Scale 


\section{Introduction}

Online activities such as social media use and online gaming have become incredibly popular and are highly enjoyable leisure activities. However, for a small minority of users, the activities engaged in on the internet can become problematic. The term 'internet addiction' has become a familiar issue in behavioral addiction research since the first empirical papers in the mid1990s (Griffiths, 1996; Young, 1996). While the positive advantages of the internet far outweigh the disadvantages, various problems associated with increased internet use have emerged over the years (e.g., cybersecurity concerns, online criminal activities, easy access to inappropriate content [self-harm, pornography], online addiction, etc.) (Ramezani, Namiranian, \& Salehi, 2012).

In the area of potentially addictive online activities, there has been increasing research into both generalized internet addiction (i.e., an umbrella term referring to the totality of an individual's activities online) and specific internet addictions (such as online gaming addiction, social media addiction, and online gambling addiction) (Griffiths \& Szabo, 2014; Pontes, Szabo \& Griffiths, 2015). Despite the ongoing debates as to whether 'internet addiction' even exists (Griffiths, Pontes \& Kuss, 2016a), most academic credence has been given to internet gaming disorder (IGD) which was listed as a tentative disorder in the latest (fifth) edition of the Diagnostic and Statistical Manual of Mental Disorders (DSM-5; American Psychiatric Association [APA], 2013) and as a fully legitimate disorder (as 'Gaming Disorder') in the latest (eleventh) revision of the International Classification of Diseases (ICD-11; World Health Organization [WHO], 2018).

According to a systematic review by Mihara and Higuchi (2017), IGD is a highly prevalent public health issue globally, with the overall prevalence of problem gaming in reviewed samples ranging from $0.7 \%$ to $15.6 \%$ of populations globally, although the prevalence rates are much lower among studies that have used nationally representative sample $-1 \%$ to $5 \%$ (Kircaburun, Pontes, Stavropoulos \& Griffiths, 2020). Despite of the fact that generalized internet addiction has been recognized as a prevalent problem among a minority of the population, it has never been classed as a formal disorder most likely because (as aforementioned) internet addiction is an umbrella term covering increasingly specific online problematic behavior such as problematic gaming and problematic social media use (Bener et al., 2019a; Kuss \& Griffiths, 2014). 
Much of the emerging evidence demonstrates that problematic internet use (irrespective of whether it is classed as an addiction and/or a disorder) is a detrimental behavior, often associated with a wide range of negative detrimental effects including (but not restricted to): physical problems (e.g., neck, shoulder, and back pain, regular headaches, dry eyes, numbness pain in the thumb, index, and middle fingers) (Bener, et al., 2019a; Bener et al., 2019b; Park et al., 2013); attention deficit/hyperactivity disorder and depression (Sariyska et al., 2015); social anxiety (Weinstein et al., 2015); decreased academic performance and poor emotional wellbeing (Rücker et al., 2015); increased academic stress (Jun \& Choi, 2015); lower levels of family functioning, life satisfaction, and problems in family interactions (Wartberg et al., 2015); alexithymia, higher levels of loneliness, and suicide (Alpaslan, Avci, Soylu, \& Guzel, 2015); and poor impulsive behaviors, and higher incidence of substance use (Reed, Osborne, Romano, \& Truzoli, 2015).

Many psychometric studies have been carried out investigating problematic internet use and there are over 20 different assessment instruments leading to challenges in documenting and comparing the actual prevalence rates across nations or regions (Kuss, Griffiths, Karila \& Billieux, J, 2014). A meta-analysis by Cheng and Li (2014) examined 164 prevalence figures derived from 80 studies $(n=89,281)$ from 31 nations across seven world regions. They reported a global prevalence estimate for internet addiction of $6.0 \%$. The highest prevalence was in the Middle East with $10.9 \%$, and the lowest was in Northern and Western Europe with 2.6\%. Nevertheless, there are several ongoing debates concerning the diagnostic criteria of internet addiction (Griffiths et al., 2016a, 2016b; Kuss et al., 2017).

One of the most psychometrically robust scales assessing problematic internet use is the nineitem Internet Disorder Scale-Short Form IDS9-SF developed by Pontes and Griffiths (2016a). They slightly modified the wording of the original nine items of the DSM-5's criteria for Internet Gaming Disorder (APA, 2013) in developing the IDS9-SF. Other similar (and psychometrically robust) scales developed by the same authors include the nine-item Internet Gaming Disorder Scale-Short Form (IGDS9-SF; Pontes \& Griffiths, 2015) and the 15-item Internet Disorder Scale (IDS-15; Pontes \& Griffiths, 2017).

In Bangladesh (where the present study was carried out), internet use has markedly increased since the first internet connection in 1996. According to the Bangladesh Telecommunication Regulatory Commission (BTRC), the total number of internet subscribers hit 99.246 million at 
the end of January 2020 (BTRC, 2020). Previous Bangladeshi studies (e.g., Afrin et al., 2017; Mamun et al., 2019a, 2019b; Islam \& Hossin, 2016; Shahnaz \& Karim, 2014) have used the Bangla Internet Addiction Test (IAT; Karim \& Nigar, 2014) or non-validated measures. However, the factor structure of the IAT has been highly variable internationally, it is of moderate length (20 items), and some of its items are very out-of-date (because the scale was developed almost 25 years ago). However, there is no short psychometric robust scale to assess problematic internet use in Bangladesh. Consequently, the present study evaluated the psychometric properties of the Bangla IDS9-SF.

\section{Methods}

\subsection{Participants}

The sample comprised 534 adolescent students (from six selected schools [secondary and higher secondary]) in Dhaka City from November 2019 to February 2020 and their age ranging from 13 to 18 years. The participants of the study comprised $61.0 \%$ males and $39.0 \%$ females, and their mean age was 15.7 years $(\mathrm{SD}=1.5)$ ranging from 13 to 18 years. A convenience sampling technique was employed to recruit the sample from the selected schools. Initially, 550 students completed a self-reported questionnaire survey. After eliminating incomplete surveys, 534 remained for the final analysis. The inclusion criterion of a participant was having internet use experience for at least one year.

\subsection{Measures}

\subsubsection{Socio-demographic measures}

Questions regarding socio-demographics were asked including age, gender, academic grade (secondary/higher secondary), relationship status (single/in a relationship), monthly family income, living together with family (yes/no), and relationship with friends (good/not so good).

\subsubsection{Internet Disorder Scale-Short Form (IDS9-SF)}

The present study translated and validated the nine-item IDS9-SF. The IDS9-SF is a unidimensional standardized psychometric tool developed by Pontes and Griffiths (2016a). This scale was used to assess the severity of internet addiction based upon users' online leisure activity (i.e., excluding academic and/or occupational Internet use) on any device with internet access during the past year (Pontes \& Griffiths, 2016a). The IDS9-SF comprises nine questions (e.g., "Have you jeopardized or lost an important relationship, career or an educational opportunity because of your online usage?") answered using a five-point Likert scale ranging 
from 1 (Never) to 5 (Very often). Total scores can range from 9 to 45, with higher scores indicating a higher degree of internet addiction. The psychometric properties of the IDS9-SF are outlined in the 'Results' section.

\subsubsection{Patient Depression Questionnaire (PHQ-9)}

The nine-item Patient Health Questionnaire (PHQ-9; Spitzer et al., 1999; Bangla version: Chowdhury et al, 2004) was used to assess depressive disorders. The scale comprises nine items responded to on a four-point Likert scale ranging from 0 (Not at all) to 3 (Nearly every day). Each item refers to problems experienced over the past two weeks (e.g., "Little interest or pleasure in doing things"). The level of depression was categorized into four groups as minimal, mild, moderate, moderately severe, and severe based on scoring $0-4,5-9,10-14,15-$ 19 , and 20-27, respectively. In the present study, those scoring moderate to severe $(\geq 10)$ were classed as having depressive positive (Kroenke, Spitzer, \& Williams, 2001). In present study, the PHQ-9 scale was found to have very good reliability (Cronbach's alpha $=0.85$ ).

\subsubsection{Generalized Anxiety Disorder Assessment (GAD-7)}

The seven-item Generalized Anxiety Disorder (GAD-7; Spitzer et al., 2006; Bangla version: Mossman et al., 2017) was used to assess the anxiety disorder of the participants. The scale comprises seven items answered on a four-point Likert scale ranging from 0 (Not at all) to 3 (Nearly every day). Each item refers to problems experienced over the past two weeks (e.g., "Feeling nervous, anxious or on edge"). The level of anxiety was categorized into four groups as minimal, mild, moderate, and severe based on scoring 0-4, 5-9, 10-14, and 15-21, respectively. In the present study, those scoring moderate to extremely severe $(\geq 10)$ were classified as having anxiety disorder positive (Spitzer et al., 2006). In present study, the GAD7 scale was found to have very good reliability (Cronbach's Alpha=0.82)

\subsection{Procedure}

\subsubsection{Translation of IDS9-SF}

The IDS9-SF was translated into Bengali. The present study executed a conceptual translation instead of a literal translation to ensure that the original meaning of an item was reserved while adapting to the Bangladeshi cultural context. The translated questionnaire was examined by four experts. All experts had very good proficiency both in Bengali and English. The most widely used standardized translation (i.e., Beaton et al., 2000) was used to perform the back translation for this scale. A pilot test was conducted on 30 students to confirm the readability 
and comprehension of the scale. These data were not included in the final analysis. A copy of the complete survey questions are available from the corresponding author on request.

\subsection{Statistical analysis}

The data were analyzed using Microsoft Excel 2010, IBM SPSS Statistics version 25 and IBM SPSS Amos 26. Microsoft Excel was used to perform data entry, editing, and sorting. Finally, an Excel file including all variables was imported in SPSS software. Descriptive statistics (e.g., frequencies, percentages, means, standard deviations, etc.) were performed using SPSS software. Item-total correlation, factor loadings for each item and Cronbach's alpha were calculated using SPSS. Confirmatory factor analysis [CFA] (e.g., the chi-square $\left[\chi^{2}\right], \chi^{2} / \mathrm{df}$, the comparative fit index [CFI], the non-normed fit index [NNFI], Tucker Lewis Fit Index [TLI], the root mean square error of approximation [RMSEA], the standardized root mean square residual [SRMR], etc.) was carried out using SPSS Amos.

\subsection{Ethics}

All procedures of the present study were performed in accordance with the Intuitional Research Ethics accordance and the Declaration of Helsinki for experiments involving humans. This study was approved by Biosafety, Biosecurity, and Ethical Clearance Committee, the ethical review broad of the Faculty of Biological Sciences, Jahangirnagar University, Savar, Dhaka1342, Bangladesh. After getting permission from the respective authorities of the selected schools, a data collection date was fixed. Formal written consent was obtained from the participants and their parent(s) prior to data collection, with clearly explained the aims and procedures of the study. Anonymity and confidentiality were ensured for all participants. Participants' information (e.g., name, telephone number, and address) was not documented or coded in the data analysis.

\section{Results}

The sample comprised $61.0 \%$ males and $39 . \%$ females, and their mean age was 15.7 years $(\mathrm{SD}=1.5)$ ranging from 13 to 18 years. Descriptive statistics for all variables are provided in Table 1. Some psychometric indicators for each of the IDS9-SF items including the mean, standard deviation, item-total correlation, and factor loadings for each item and Cronbach's alpha if item deleted along with skewness and kurtosis are outlined in Table 2. All items yielded skewness and kurtosis values within the \pm 1.08 range, indicating that they were 
normally distributed. The item-total correlations and factor loadings for each item were all satisfactory. The values from Cronbach's alpha if item deleted were also all satisfactory.

\subsection{Construct validity}

With regard to CFA, the chi-square $\left(\chi^{2}\right), \chi^{2} / \mathrm{df}$, CFI, NNFI, TLI, RMSEA, and SRMR were performed for fit estimation (see Table 3). Thresholds and conventional fit indices were applied to investigate the goodness of fit of the model under statistical analysis: $\chi^{2} / \mathrm{df}[1: 4]$, CFI (0.90:0.95), NNFI (0.90;0.95), TLI (0.90;0.95), RMSEA $(0.05 ; 0.08)$, SRMR $(0.05 ; 0.08)$, (Bentler, 1990; Bentler \& Bonett, 1980; Hooper, Coughlan, \& Mullen, 2008; Hu \& Bentler, 1999). Compared with aforementioned thresholds, the findings represented the model as an excellent fit to data: $\chi^{2}=117.08, \chi^{2} / \mathrm{df}=4.34, \mathrm{CFI}=0.93, \mathrm{NNFI}=0.91, \mathrm{TLI}=0.90, \mathrm{RMSEA}=0.08$, and $\mathrm{SRMR}=0.035$.

Factor loadings for the nine items of the IDS9-SF ranged between 0.43 and 0.66 (see Figure 2) that were acceptable. The acceptability factor was greater than the load value of 0.32 (Tabachnick \& Fidell, 2001). The composition reliability (CR) was also calculated to examine convergent validity. The calculated value of CR was 0.82. According to Fornell and Larcker, convergent validity is supported if the CR is higher than 0.5 (Fornell \& Larcker, 1981).

\subsection{Nomological and convergent validity}

Full bootstrapped structural equation modeling was performed on the data to examine the nomological validity of the IGD construct. The structural model included IGD as the predictor of depression, and anxiety because several empirical studies have reported these associations (Lehenbauer-Baum et al., 2015; Stetina et al., 2011; Wei et al., 2012). The findings produced an adequate fit to the data $\left(\chi^{2}=717.9, \mathrm{df}=272, \mathrm{CFI}=0.92, \mathrm{TLI}=0.90, \mathrm{RMSEA}=0.06[90 \% \mathrm{CI}\right.$ : 0.051-0.060], SRMR=0.05). In terms of the variance explained $\left(\mathrm{R}^{2}\right)$ for each outcome in the model, IDS explained $23.4 \%$ of the variance in depression $\left(\mathrm{R}^{2}=0.234, p<.001\right)$, and $19.8 \%$ of the variance in anxiety $\left(\mathrm{R}^{2}=0.198, p<.001\right)$. In relation to convergent validity, total IDS9-SF score was positively and significantly correlated with both PHQ-9 score $(r=0.41, p<.001)$ and GAD-7 score $(r=0.36, p<.001)$.

\subsection{Reliability analysis}

With regard to calculating the IDS9-SF's internal consistency and reliability coefficients, Cronbach's alpha and inter-item correlation matrix were performed. The coefficients of 
Cronbach's alpha were calculated. Cronbach's alpha for the total IDS9-SF was 0.82 . The interitem correlation matrix (Table 3) contained no negative values, indicating that the items were assessing the same construct. Therefore, the CR of the IDS9-SF was very good $(\alpha=0.82)$, which is well beyond the accepted threshold of 0.70 (Fornell \& Larcker, 1981; Hair, Black, Babin, Anderson, \& Tatham, 1998).

\section{Discussion}

The nine-item Internet Disorder Scale-Short Form (IDS9-SF) is a standardized psychometric instrument that assesses problematic internet use. Like its 'sister' instrument, the nine-item Internet Gaming Disorder Scale-Short Form, both scales are robust psychometric tools that assess online disorders and both were based on the DSM-5 criteria for IGD and are among the most popular instruments used in recent years and in different languages and cultural contexts (Bernaldo-de-Quirós et al., 2019).

The present study was designed to evaluate the psychometric properties of the Bangla version of the IDS9-SF. The analysis of the present study indicated that the item-total correlations and factor loadings for each item were satisfactory. Confirmatory factor analysis demonstrated the model had an excellent fit to the data. The Cronbach's alpha $(\alpha=0.82)$ indicated very good reliability. Results also demonstrated good construct validity because gaming disorder (IDS9SF score) was positively and significantly correlated with both depression (PHQ-9 score) and anaxiety (GAD-7 score).

As the IDS9-SF was derived from the same source as the IGDS9-SF, it is useful to note the comparisons of reliability with the previous studies conducted among different languages or cultures on both IDS9-SF and IGDS9-SF (see Table 4). Compared to Cronbach's alpha $(\alpha=0.82)$ in the present study, the reliabilities of IDS9-SF and IGD9-SF were very good in previous studies: Italian IGDS9-SF ( $\alpha=0.89$; Monacis et al., 2016), Portuguese IGDS9-SF ( $\alpha=$ 0.87; Pontes \& Griffiths, 2016a), Slovenian IGDS9-SF ( $\alpha=0.93$; Pontes et al., 2016), Turkish IDS9-SF ( $\alpha=0.85$; Bener et al., 2019a) and Turkish IGD9-SF ( $\alpha=0.82$; Arıcak et al., 2018); Hong Kong version ( $\alpha=0.903$; Yam et al., 2019); Spanish version IGDS9-SF ( $\alpha=0.85$; Beranuy et al., 2020); and Brazilian version IGDS9-SF ( $\alpha=0.82$; Severo et al., 2020).

In relation to other validity indicators, the chi-square $\left(\chi^{2}\right), p$-value, $\chi^{2} / \mathrm{df}$, the comparative fit index (CFI), the non-normed fit index (NNFI), Tucker Lewis Fit Index (TLI), the root mean 
square error of approximation (RMSEA), and the standardized root mean square residual (SRMR) all exceeded psychometrically acceptable thresholds.

\subsection{Limitations}

Although the findings encountered regarding the psychometric properties of the Bangla version IDS9-SF were very satisfactory overall, there are some potential limitations worth noting. Firstly, the data were collected using a self-report survey. Therefore, well-known common methods biases could have been present (e.g., memory recall, social desirability biases). Thirdly, the modest sized sample is the only representative of selected schools in Bangladesh and might not be representative of schools in other countries. Therefore, further studies employing bigger samples from more representative school populations are required. Another limitation was that the present study did not test validity and reliability on an adult sample (although the scale has been used among adolescent samples previously).

\section{Conclusion}

The findings of the present study demonstrate that problematic internet use can be reliably and validly assessed using the Bangla version Internet Disorder Scale-Short Form (IDS9-SF). For the first time, the Bangla version of this short scale was used to assess problematic internet use in the context of Bangladeshi cultural background and for this reason, more research on problematic internet use utilizing this scale is envisaged. The instrument will aid the conducting of psychometric research and help policymakers and administrators to design internet management strategies including prevention, diagnosis, control, and treatment of problematic internet use. Finally, it should be reiterated that the Bangla Internet Disorder Scale-Short Form (IDS9-SF) appears to be a very good instrument to examine problematic internet use among the Bangladeshi population in future studies.

\section{Role of the funding source}

Self-funded

\section{Conflict of interest}

The authors declare that they have no potential conflict of interest for the publication of this article.

\section{Authors contributions}


MSI, MER, and MSM conceptualized the initial phases of the study. MER collected data; MSI analyzed data; MSI drafted initial versions of the manuscript; MER and MSM edited the manuscript. Finally, MDG contributed to the editing of the manuscript for critical content. All authors have approved the final version of the manuscript.

\section{Acknowledgment}

Firstly, the authors would like to thank all of the respondents who participated in this study voluntarily. Secondly, the authors are very grateful to parents of all respondents for consent as well as respective authorities for formal permission. Furthermore, the authors highly appreciate the contribution of Fatema Akter Bethi, Sayeda Sumaiya Nahrin, Rabeya Akter Mohua, Md Rayhan Sakib, Tareq Mahmud, Sanzida Amin, and Tasnimul Ahsan Shakkhor, (Department of Public Health and Informatics, Jahangirnagar University, 48 Batch) during data collection periods and input.

\section{References}

Afrin, D., Islam, M. U., Rabbiand, F., \& Hossain, A. (2017). The school-level factors associated with internet addiction among adolescents: A cross-sectional study in Bangladesh. Journal of Addiction and Dependence, 3(2), 170-174.

Alpaslan, A. H., Avci, K., Soylu, N., \& Guzel, H. I. (2015). The association between problematic internet use, suicide probability, alexithymia and loneliness among Turkish medical students. Journal of Psychiatry, 18, 1000208.

American Psychiatric Association (2013). Diagnostic and statistical manual of mental disorders (5th ed.). Arlington, VA: American Psychiatric Publishing.

Arıcak, O. T., Dinc, M., Yay, M., \& Griffiths, M. D. (2018). Adapting the short form of the internet gaming disorder scale into Turkish: Validity and reliability. Addicta: The Turkish Journal on Addictions, 5, 615-628.

Bangladesh Telecommunication Regulatory Commission (2020). Internet subscribers in Bangladesh January, 2020. Retrieved March 21, 2020, from: http://www.btrc.gov.bd/telco/internet 
Beaton, D. E., Bombardier, C., Guillemin, F., \& Ferraz, M. B. (2000). Guidelines for the process of cross-cultural adaptation of self-report measures. Spine, 25(24), 3186-3191.

Bener, A., Griffiths, M. D., Baysoy, N. G., Catan, F., \& Yurtseven, E. (2019). Internet addiction and the psychometric properties of the Nine-item Internet Disorder Scale-Short Form: An application of Rasch Analysis. Addiction and Health, 11(4), 234-242.

Bener, A., Yildirim, E., Torun, P., Çatan, F., Bolat, E., Alıç, S., ... Griffiths, M. D. (2019). Internet addiction, fatigue, and sleep problems among adolescent students: A large-scale study. International Journal of Mental Health and Addiction, 17(4), 959-969.

Bentler, P. M. (1990). Comparative fit indexes in structural models. Psychological Bulletin, 107(2), 238.

Bentler, P. M., \& Bonett, D. G. (1980). Significance tests and goodness of fit in the analysis of covariance structures. Psychological Bulletin, 88(3), 588.

Beranuy, M., Machimbarrena, J. M., Vega-Osés, M. A., Carbonell, X., Griffiths, M. D., Pontes, H. M., \& González-Cabrera, J. (2020). Spanish validation of the Internet Gaming Disorder Scale-Short Form (IGDS9-SF): Prevalence and relationship with online gambling and quality of life. International Journal of Environmental Research and Public Health, 17(5), 1562.

Bernaldo-de-Quirós, M., Labrador-Méndez, M., Sánchez-Iglesias, I., \& Labrador, F. J. (2019). Instrumentos de medida del trastorno de juego en internet en adolescentes y jóvenes según criterios DSM-5: una revisión sistemática. Adicciones, epub ahead of print.

Cheng, C., \& Li, A. Y. L. (2014). Internet addiction prevalence and quality of (real) life: A meta-analysis of 31 nations across seven world regions. Cyberpsychology, Behavior, and Social Networking, 17(12), 755-760.

Chowdhury, A., Ghosh, S., \& Sanyal, D. (2004). Bengali adaptation of brief patient health questionnaire for screening depression at primary care. Journal of the Indian Medical Association, 102(10), 544-547. 
Cronbach, L. J., \& Meehl, P. E. (1955). Construct validity in psychological tests. Psychological Bulletin, 52(4), 281-302.

Fornell, C., \& Larcker, D. F. (1981). Evaluating structural equation models with unobservable variables and measurement error. Journal of Marketing Research, 18(1), 39-50.

Griffiths, M. D. (1996). Internet addiction: An issue for clinical psychology? Clinical Psychology Forum, 97, 32-36.

Griffiths, M. D., Pontes, H. M. \& Kuss, D. J. (2016). Online addictions: Conceptualizations, debates and controversies. Addicta: The Turkish Journal on Addictions, 3(2), 151-164.

Griffiths M. D. \& Szabo, A. (2014). Is excessive online usage a function of medium or activity? An empirical pilot study. Journal of Behavioral Addictions, 3, 74-77.

Griffiths, M. D., Van Rooij, A. J., Kardefelt-Winther, D., Starcevic, V., Kiraly, O., ... Demetrovics, Z.. (2016). Working towards an international consensus on criteria for assessing Internet gaming disorder: A critical commentary on Petry et al. (2014). Addiction, 111(1), 167175.

Hair, J. F., Black, W. C., Babin, B. J., Anderson, R. E., \& Tatham, R. L. (1998). Multivariate data analysis (Vol. 5). Upper Saddle River, NJ: Prentice Hall

Hooper, D., Coughlan, J., \& Mullen, M. R. (2008). Structural equation modelling: Guidelines for determining model fit. Electronic Journal of Business Research Methods, 6(1), 53-60.

Hu, L., \& Bentler, P. M. (1999). Cutoff criteria for fit indexes in covariance structure analysis: Conventional criteria versus new alternatives. Structural Equation Modeling, 6(1), 1-55.

Islam, M. A., \& Hossin, M. Z. (2016). Prevalence and risk factors of problematic internet use and the associated psychological distress among graduate students of Bangladesh. Asian Journal of Gambling Issues and Public Health, 6, 1-11.

Jun, S., \& Choi, E. (2015). Academic stress and Internet addiction from general strain theory 
framework. Computers in Human Behavior, 49, 282-287.

Karim, A. K. M. R., \& Nigar N. (2014). The Internet Addiction Test: Assessing its psychometric properties in Bangladeshi culture. Asian Journal of Psychiatry, 10, 75-83.

Kircaburun, K., Pontes, H.M., Stavropoulos, V. \& Griffiths, M.D. (2020). A brief psychological overview of disordered gaming. Current Opinion in Psychology. Epub ahead of print. https://doi.org/10.1016/j.copsyc.2020.03.004

Kroenke, K., Spitzer, R. L., \& Williams, J. B. W. (2001). The PHQ-9: Validity of a brief depression severity measure. Journal of General Internal Medicine, 16(9), 606-613.

Kuss, D., \& Griffiths, M. (2014). Internet addiction in psychotherapy. London: Palgrave.

Kuss, D. J., Griffiths, M. D., Karila, L., \& Billieux, J. (2014). Internet addiction: A systematic review of epidemiological research for the last decade. Current Pharmaceutical Design, 20(25), 4026-4052.

Kuss, D. J., Griffiths, M. D., \& Pontes, H. M. (2017). Chaos and confusion in DSM-5 diagnosis of Internet Gaming Disorder: Issues, concerns, and recommendations for clarity in the field. Journal of Behavioral Addictions, 6(2), 103-109.

Lehenbauer-Baum, M., Klaps, A., Kovacovsky, Z., Witzmann, K., Zahlbruckner, R., \& Stetina, B. U. (2015). Addiction and engagement: An explorative study toward classification criteria for internet gaming disorder. Cyberpsychology, Behavior, and Social Networking, 18(6), 343349.

Mamun, M. A., Hossain, M. S., Siddique, A. B., Sikder, M. T., Kuss, D. J., \& Griffiths, M. D. (2019a). Problematic internet use in Bangladeshi students: the role of socio-demographic factors, depression, anxiety, and stress. Asian Journal of Psychiatry, 44, 48-54.

Mamun, M. A., Rafi, M. A., Al Mamun, A. S, Hasan, M. Z., Akter, K., Hsan, K., \& Griffiths, M. D. (2019b). Prevalence and psychiatric risk factors of excessive internet use among 
Northern Bangladeshi job-seeking graduate students: A pilot study. International Journal of Mental Health and Addiction. Epub ahead of print. doi: 10.1007/s11469-019-00066-5.

Mihara, S., \& Higuchi, S. (2017). Cross-sectional and longitudinal epidemiological studies of I nternet gaming disorder: A systematic review of the literature. Psychiatry and Clinical Neurosciences, 71(7), 425-444.

Monacis, L., Palo, V. de, Griffiths, M. D., \& Sinatra, M. (2016). Validation of the Internet Gaming Disorder Scale - Short-Form (IGDS9-SF) in an Italian-speaking sample. Journal of Behavioral Addictions, 5(4), 683-690.

Mossman, S. A., Luft, M. J., Schroeder, H. K., Varney, S. T., Fleck, D. E., Barzman, D. H., ... Strawn, J. R. (2017). The Generalized Anxiety Disorder 7-item scale in adolescents with generalized anxiety disorder: Signal detection and validation. Annals of Clinical Psychiatry: 29(4), 227-234A.

Park, S., Hong, K.-E. M., Park, E. J., Ha, K. S., \& Yoo, H. J. (2013). The association between problematic internet use and depression, suicidal ideation and bipolar disorder symptoms in Korean adolescents. Australian \& New Zealand Journal of Psychiatry, 47(2), 153-159.

Pontes, H. M., \& Griffiths, M. D. (2015). Measuring DSM-5 Internet gaming disorder: Development and validation of a short psychometric scale. Computers in Human Behavior, 45, $137-143$.

Pontes, H. M., \& Griffiths, M. D. (2016a). The development and psychometric properties of the Internet Disorder Scale-Short Form (IDS9-SF). Addicta: The Turkish Journal on Addictions, 3(2).

Pontes, H. M., \& Griffiths, M. D. (2016b). Portuguese validation of the internet gaming disorder scale-short-form. Cyberpsychology, Behavior, and Social Networking, 19(4), 288293.

Pontes, H. M., \& Griffiths, M. D. (2017). The development and psychometric evaluation of the Internet Disorder Scale (IDS-15). Addictive Behaviors, 64, 261-268. 
Pontes, H. M., Macur, M. \& Griffiths, M. D. (2016). Internet Gaming Disorder among Slovenian primary schoolchildren: Findings from a nationally representative sample of adolescents. Journal of Behavioral Addictions, 5, 304-310.

Pontes, H. M., Szabo, A. \& Griffiths, M. D. (2015). The impact of Internet-based specific activities on the perceptions of internet addiction, quality of life, and excessive usage: A crosssectional study. Addictive Behaviors Reports, 1, 19-25.

Ramezani, M., Namiranian, N., \& Salehi, M. (2012). Validity and reliability of the Chen internet addiction scale. Journal of Fundamentals of Mental Health, 14(55), 45-236.

Reed, P., Osborne, L. A., Romano, M., \& Truzoli, R. (2015). Higher impulsivity after exposure to the internet for individuals with high but not low levels of self-reported problematic internet behaviours. Computers in Human Behavior, 49, 512-516.

Rücker, J., Akre, C., Berchtold, A., \& Suris, J. (2015). Problematic Internet use is associated with substance use in young adolescents. Acta Paediatrica, 104(5), 504-507.

Sariyska, R., Reuter, M., Lachmann, B., \& Montag, C. (2015). Attention deficit/hyperactivity disorder is a better predictor for problematic Internet use than depression: Evidence from Germany. Journal of Addiction Research \& Therapy, 6(209), 1-6.

Severo, R. B., Barbosa, A. P. P. N., Fouchy, D. R. C., Coelho, F. M. da C., Pinheiro, R. T., de Figueiredo, V. L. M., ... Pinheiro, K. A. T. (2020). Development and psychometric validation of Internet Gaming Disorder Scale-Short-Form (IGDS9-SF) in a Brazilian sample. Addictive Behaviors, 103, 106191.

Shahnaz, I., \& Karim, A. K. M. R. (2014). The impact of Internet addiction on life satisfaction and life engagement in young adults. Universal Journal of Psychology, 2(9), 273-284.

Spitzer, R.L., Kroenke, K., Williams, J.B.W., \& Patient Health Questionnaire Primary Care Study Group (1999). Validation and utility of a self-report version of PRIME-MD: The PHQ primary care study. JAMA, 282(18), 1737-1744. 
Spitzer, R. L., Kroenke, K., Williams, J. B. W., \& Löwe, B. (2006). A brief measure for assessing Generalized Anxiety Disorder: The GAD-7. Archives of Internal Medicine, 166(10), 1092-1097.

Stetina, B. U., Kothgassner, O. D., Lehenbauer, M., \& Kryspin-Exner, I. (2011). Beyond the fascination of online-games: Probing addictive behavior and depression in the world of onlinegaming. Computers in Human Behavior, 27(1), 473-479.

Tabachnick, B. G., \& Fidell, L. S. (2001). Using multivariate statistics. Boston, MA: Allyn \& Bacon/Pearson Education.

Wartberg, L., Kriston, L., Kammerl, R., Petersen, K.-U., \& Thomasius, R. (2015). Prevalence of pathological internet use in a representative German sample of adolescents: Results of a latent profile analysis. Psychopathology, 48(1), 25-30.

Wei, H.-T., Chen, M.-H., Huang, P.-C., \& Bai, Y.-M. (2012). The association between online gaming, social phobia, and depression: an internet survey. BMC Psychiatry, 12(1), 92.

Weinstein, A., Dorani, D., Elhadif, R., Bukovza, Y., Yarmulnik, A., \& Dannon, P. (2015). Internet addiction is associated with social anxiety in young adults. Annals of Clinical Psychiatry, 27(1), 4-9.

Yam, C-Y., Pakpour, A., Griffiths, M. D., Yau, W-Y., Lo, C-Y. M., Jennifer M. T. Ng, J. M. T., Lin, C. Y., Leung, H. (2019). Psychometric testing of three Chinese online-related addictive behavior instruments among Hong Kong university students. Psychiatric Quarterly, 90, 117128.

Young, K. (1996). Psychology of computer use: XL. Addictive use of the Internet: A case that breaks the stereotype. Psychological Reports, 79, 899-902. 
Table 1: General characteristics of participants $(\mathrm{N}=534)$

\begin{tabular}{|c|c|c|}
\hline Variables & $\mathbf{n}$ & $(\%)$ \\
\hline \multicolumn{3}{|l|}{ Age } \\
\hline $13-14$ & 139 & $(26.0)$ \\
\hline $15-16$ & 206 & $(38.6)$ \\
\hline $17-18$ & 189 & $(35.4)$ \\
\hline \multicolumn{3}{|l|}{ Gender } \\
\hline Male & 326 & $(61.0)$ \\
\hline Feamle & 208 & $(39.0)$ \\
\hline \multicolumn{3}{|l|}{ Academic Grade } \\
\hline Secondary & 304 & $(56.9)$ \\
\hline Higher secondary & 230 & $(43.1)$ \\
\hline \multicolumn{3}{|l|}{ Relationship status } \\
\hline Married & 4 & $(.7)$ \\
\hline Unmarried & 450 & $(84.3)$ \\
\hline In a relationship & 80 & $(15.0)$ \\
\hline \multicolumn{3}{|c|}{ Monthly family income } \\
\hline$>10,000 \mathrm{BDT}$ & 114 & $(21.3)$ \\
\hline $10,000-20,000 \mathrm{BDT}$ & 198 & $(37.1)$ \\
\hline$>20000 \mathrm{BDT}$ & 222 & $(41.6)$ \\
\hline \multicolumn{3}{|l|}{ Living with family } \\
\hline Yes & 460 & $(86.1)$ \\
\hline No & 74 & $(13.9)$ \\
\hline \multicolumn{3}{|c|}{ Average internet use hours } \\
\hline$<1$ hours & 169 & $(31.6)$ \\
\hline $1-2$ hours & 176 & $(33.0)$ \\
\hline 3-4 hours & 108 & $(20.2)$ \\
\hline$>4$ hours & 81 & $(15.2)$ \\
\hline \multicolumn{3}{|l|}{ Social media use } \\
\hline$<1$ hour & 265 & $(49.6)$ \\
\hline 1-3 hours & 184 & $(34.5)$ \\
\hline$>3$ hours & 85 & (15.9) \\
\hline
\end{tabular}


Table 2: Mean, standard deviation, item-total correlation, factor loadings for each item and Cronbach's alpha if item deleted of the Internet Disorder Scale-Short Form (IGS9-SF).

\begin{tabular}{lllllllc}
\hline Items & $\mathrm{M}$ & $\mathrm{SD}$ & $\mathrm{IT}$ & $\mathrm{CFE}$ & $\mathrm{CAID}$ & Skewness & Kurtosis \\
\hline IDS1 & 2.39 & 1.27 & 0.50 & 0.62 & 0.81 & 0.45 & -0.90 \\
IDS2 & 2.20 & 1.18 & 0.56 & 0.68 & 0.80 & 0.59 & -0.64 \\
IDS3 & 2.21 & 1.23 & 0.39 & 0.51 & 0.82 & 0.55 & -0.80 \\
IDS4 & 2.39 & 1.33 & 0.55 & 0.67 & 0.80 & 0.49 & -0.96 \\
IDS5 & 2.07 & 1.28 & 0.59 & 0.71 & 0.80 & 0.88 & -0.47 \\
IDS6 & 2.11 & 1.25 & 0.58 & 0.70 & 0.80 & 0.83 & -0.45 \\
IDS7 & 1.95 & 1.25 & 0.57 & 0.69 & 0.80 & 1.05 & -0.11 \\
IDS8 & 2.38 & 1.27 & 0.50 & 0.62 & 0.81 & 0.48 & -0.79 \\
IDS9 & 1.95 & 1.29 & 0.47 & 0.60 & 0.81 & 1.08 & -0.11 \\
\hline
\end{tabular}

Note: $\mathrm{M}=$ Arithmetic mean; $\mathrm{SD}=$ Standard deviation; $\mathrm{IT}=$ corrected item-total correlation; $\mathrm{CFE}=$ Standardized factorial loads; CAID $=$ Cronbach's Alpha if Item Deleted.

Table 3: Inter-item correlation matrix for the Internet Disorder Scale-Short Form (IDS9-SF).

\begin{tabular}{|c|c|c|c|c|c|c|c|c|c|}
\hline Items & IDS1 & IDS2 & IDS3 & IDS4 & IDS5 & IDS6 & IDS7 & IDS8 & IDS9 \\
\hline IDS1 & 1 & $.507 * *$ & $.302 * *$ & $.292 * *$ & $.345^{* *}$ & $.306^{* *}$ & $.301 * *$ & $.306^{* *}$ & $.267 * *$ \\
\hline IDS2 & $.507 * *$ & 1 & $.358 * *$ & $.358 * *$ & $.365 * *$ & $.405 * *$ & $.321 * *$ & $.345^{* *}$ & $.251 * *$ \\
\hline IDS3 & $.302 * *$ & $.358^{* *}$ & 1 & $.235^{* *}$ & $.276^{* *}$ & $.278^{* *}$ & $.251 * *$ & $.299 * *$ & $.094 *$ \\
\hline IDS4 & $.292 * *$ & $.358^{* *}$ & $.235^{* *}$ & 1 & $.458 * *$ & $.378 * *$ & $.369^{* *}$ & $.335 * *$ & $.395 * *$ \\
\hline IDS5 & $.345^{* *}$ & $.365^{* *}$ & $.276^{* *}$ & $.458^{* *}$ & 1 & $.433 * *$ & $.434 * *$ & $.341 * *$ & $.381^{* *}$ \\
\hline IDS6 & $.306^{* *}$ & $.405^{* *}$ & $.278^{* *}$ & $.378^{* *}$ & $.433 * *$ & 1 & $.475^{* *}$ & $.348^{* *}$ & $.382 * *$ \\
\hline IDS7 & $.301 * *$ & $.321 * *$ & $.251 * *$ & $.369^{* *}$ & $.434 * *$ & $.475 * *$ & 1 & $.351^{* *}$ & $.423^{* *}$ \\
\hline IDS8 & $.306^{* *}$ & $.345^{* *}$ & $.299 * *$ & $.335^{* *}$ & $.341 * *$ & $.348 * *$ & $.351^{* *}$ & 1 & $.277 * *$ \\
\hline IDS9 & $.267 * *$ & $.251^{* *}$ & $.094 *$ & $.395^{* *}$ & $.381 * *$ & $.382 * *$ & $.423 * *$ & $.277 * *$ & 1 \\
\hline
\end{tabular}

$* *$ Correlation is significant at the $\mathrm{p}<0.01$ level (2-tailed).

*Correlation is significant at the $\mathrm{p}<0.05$ level (2-tailed). 
Table 4: Psychometric properties of various versions for both IGDS9-SF and IDS9-SF.

\begin{tabular}{|c|c|c|c|c|c|c|}
\hline Studies & Scales & Year & Version & $\begin{array}{l}\text { Sample } \\
\text { size }\end{array}$ & Age (SD) & $\begin{array}{l}\text { Cronbach's } \\
\text { alpha }\end{array}$ \\
\hline $\begin{array}{l}\text { Pontes \& Griffiths } \\
(2015)\end{array}$ & IGDS9-SF & 2015 & English & 1,060 & $27.0(9.02)$ & 0.87 \\
\hline Monacis et al. (2016) & IGDS9-SF & 2016 & Italian & 757 & $21.62(3.90)$ & 0.89 \\
\hline $\begin{array}{l}\text { Pontes \& Griffiths } \\
(2016 a)\end{array}$ & IGDS9-SF & 2016 & Portuguese & 509 & $13.0(1.64)$ & 0.87 \\
\hline $\begin{array}{l}\text { Pontes \& Griffiths } \\
(2016 b)\end{array}$ & IDS9-SF & 2016 & English & 1,100 & $33.0 \pm 12.33)$ & 0.93 \\
\hline Pontes et al. (2016) & IGDS9-SF & 2016 & Slovenian & 1071 & $13.44(0.59)$ & 0.93 \\
\hline Arıcak et al. (2018) & IGDS9-SF & 2018 & Turkish & 455 & $12.50(1.20)$ & 0.82 \\
\hline Bener et al. (2019a) & IDS9-SF & 2019 & Turkish & 1988 & $18-25$ & 0.85 \\
\hline Yam et al. (2019) & IGDS9-SF & 2019 & Hong Kong & 307 & $21.64(8.11)$ & 0.90 \\
\hline Beranuy et al. (2020) & IGDS9-SF & 2020 & Spanish & 535 & $18.35(2.13)$ & 0.85 \\
\hline Severo et al. (2020) & IGDS9-SF & 2020 & Brazilian & 610 & $20.3(5.4)$ & 0.82 \\
\hline
\end{tabular}




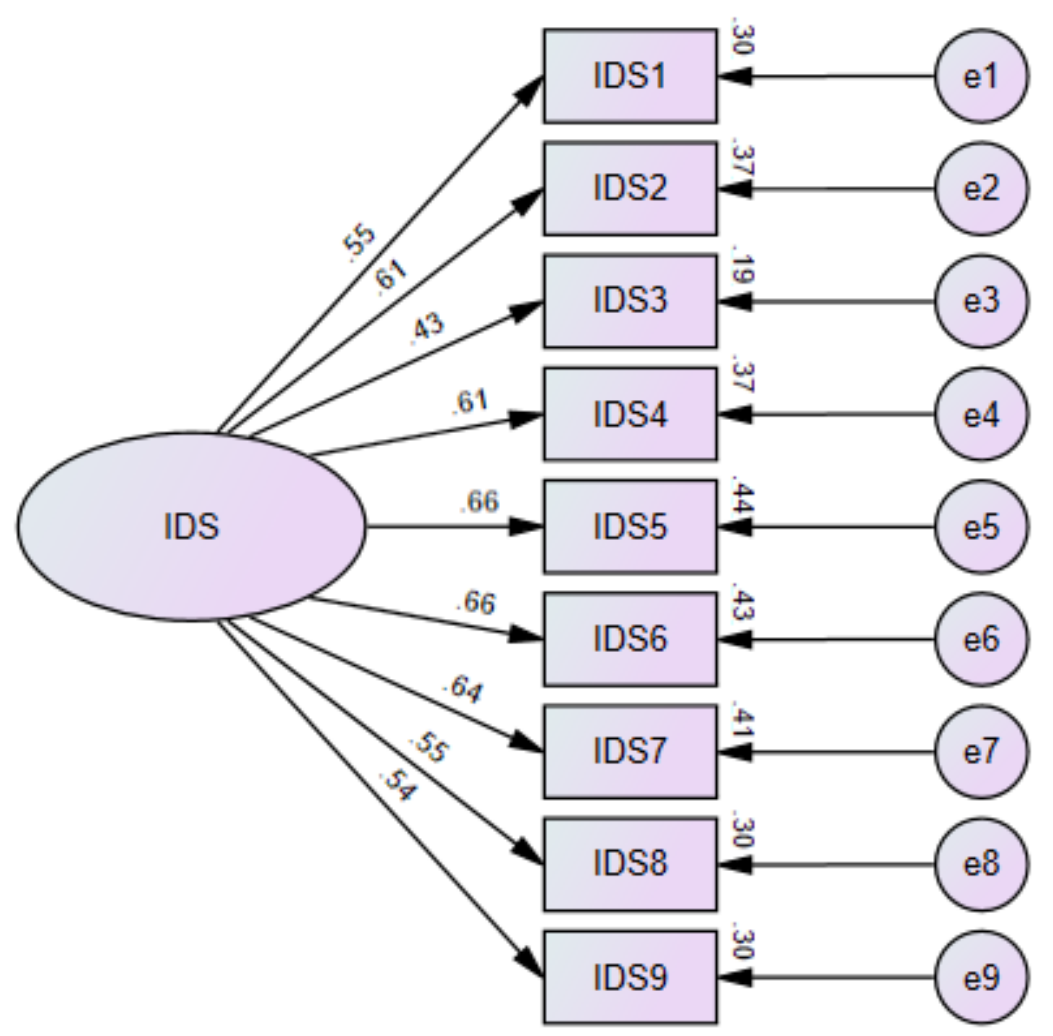

Figure 1: Graphical summary of the Confirmatory Factor Analysis results obtained from the nine items of the Internet Disorder Scale-Short Form (IDS9-SF) (N=534). 


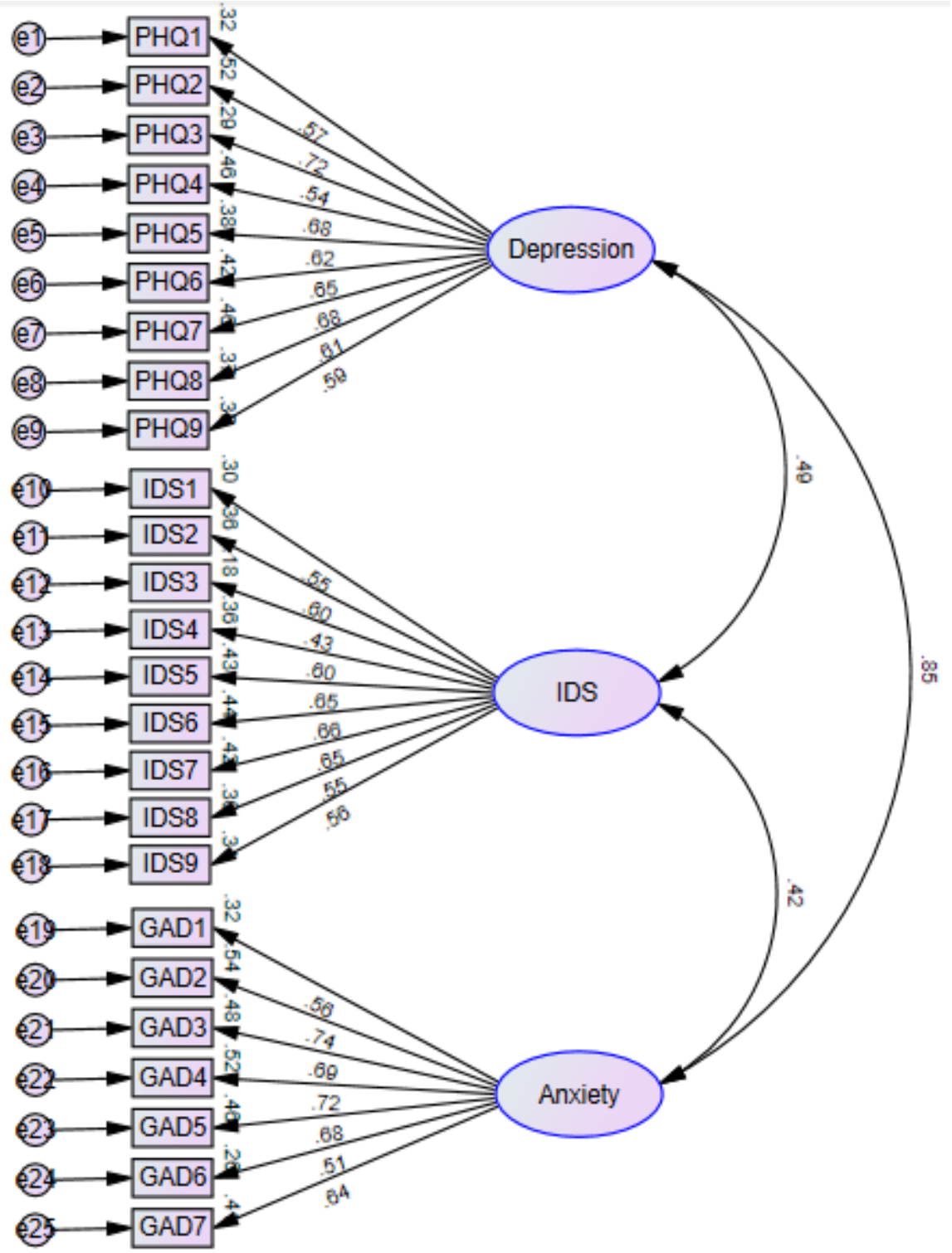

Figure 2: Graphical summary of the Confirmatory Factor Analysis results obtained from the IDS9-SF, PHQ-9, and GAD-7 (N=534). 